\title{
Endovascular treatment strategies for cerebral vasospasm
}

\author{
Stefan A. Mindea, M.D., Benson P. Yang, M.D., Bernard R. Bendok, M.D., \\ JEFFReY W. Miller, M.D., AND H. HunT BATJER, M.D.
}

Department of Neurological Surgery, Feinberg School of Medicine, Northwestern University, Chicago, Illinois

\begin{abstract}
$\checkmark$ Cerebral vasospasm is a significant cause of morbidity and mortality in patients who have sustained a subarachnoid hemorrhage from aneurysm rupture. Symptomatic cerebral vasospasm is also a strong predictor of poor clinical outcome and has thus drawn a great deal of interest from cerebrovascular surgeons. Although medical management is the cornerstone of treatment for this condition, endovascular intervention may be warranted for those in whom this treatment fails and in whom symptomatic vasospasm subsequently develops. The rapid advancements in endovascular techniques and pharmacological agents used to combat this pathological state continue to offer promise in broadening the available treatment armamentarium. In this article the authors discuss the rationale and basis for using the various endovascular options for the treatment of cerebral vasospasm, and they also discuss the limitations, complications, and efficacy of these treatment strategies in regard to neurological condition and outcome.
\end{abstract}

\section{KEY WORDS • vasospasm • aneurysm • subarachnoid hemorrhage • endovascular therapy}

$\mathrm{C}$ EREBRAL vasospasm following aneurysmal SAH continues to be a leading cause of morbidity and mortality and is a significant independent risk factor for poor outcome after SAH., ${ }^{4,33}$ Vasospasm is defined as the delayed, reversible narrowing of cerebral vessels, most commonly involving the proximal arteries composing the circle of Willis, and it occurs 4 to 14 days after SAH. Our understanding of the pathophysiological mechanisms involved is incomplete, but the presence of subarachnoid clot around the affected vessels has been implicated as the primary causative factor in the development of vasospasm. In addition to the Hunt and Hess grade, the initial presence, volume, density, and duration of clot as seen on CT scans have been proven to be powerful predictors for the occurrence of vasospasm. ${ }^{20,50,58,62}$ Symptomatic spasm is also a strong predictor of poor clinical outcome and in-hospital deaths. ${ }^{29}$

Because vasospasm is first and foremost a hemodynamic problem, current treatment measures are geared toward optimizing cerebral perfusion and minimizing secondary brain injury. Hypervolemia and hypertension, in addition to oral nimodipine, are the conceptual mainstays in the achievement of this goal. However, since Ecker and Riemenschneider ${ }^{14}$ first introduced the concept of vasospasm after SAH, neurosurgeons have been compelled to develop new and creative strategies to address this important clinical state. For patients whose condition is refrac-

Abbreviations used in this paper: $\mathrm{ACA}=$ anterior cerebral artery; $\mathrm{CBF}=$ cerebral blood flow; $\mathrm{CT}=$ computed tomography; ICA = internal carotid artery; ICP = intracranial pressure; $\mathrm{MCA}=$ middle cerebral artery; $\mathrm{SAH}=$ subarachnoid hemorrhage; $\mathrm{TCD}=$ transcranial Doppler. tory to maximal medical therapy, endovascular therapy remains an important therapeutic intervention to address cerebral vasospasm mechanically and pharmacologically. Our goal in this paper was to discuss the rationale and basis for using the various endovascular options for the treatment of cerebral vasospasm and to discuss the limitations, complications, and efficacy of these treatment strategies in this neurological condition.

\section{Transluminal Balloon Angioplasty}

Cerebral vasospasm that is refractory to maximal medical therapy represents a potential indication for endovascular therapy after the ruptured cerebral aneurysm has been secured. The treatment objective is to prevent cerebral ischemia and infarction by restoring adequate blood flow by several different methods: transluminal balloon angioplasty, intraarterial injection of pharmacological agents, or a combination of these two treatments. In 1984, Zubkov and colleagues ${ }^{70}$ first reported treating 33 patients with SAH by using balloon catheters to dilate 105 vasospastic arteries, thus demonstrating the technical capacity to treat these stenotic vessels with endovascular techniques. Since that time, investigators have demonstrated the safety and efficacy of this treatment modality in numerous case series. Despite the excellent results of transluminal balloon angioplasty as demonstrated on angiographic studies, varying degrees of success in reversal of neurological deficits caused by cerebral vasospasm have been reported, ranging from 31 to $93 \%$ of patients with improvement after treatment. ${ }^{7,11,17,66}$ After reviewing select clinical case series of endovascular therapy for cerebral vasospasm, Hoh and Ogilvy ${ }^{28}$ estimated that $62 \%$ of patients improved clinically after transluminal balloon angioplasty. Thus, when 
comparing procedural complications with the poor natural history of vasospasm, transluminal balloon angioplasty has emerged as an important therapeutic intervention in selected patients.

Transluminal balloon angioplasty has been used most effectively in reversing vasospasm in large, proximal segments of cerebral vessels composed of thick muscular walls (Fig. 1). Typically, vasospasm affects the $A_{1}$ segment of the ACA and the $M_{1}$ and $M_{2}$ segments of the MCA, and is less frequently seen in the $P_{1}$ segment of the posterior cerebral artery or in vessels originating from the vertebrobasilar system. Although the angiographic goal of transluminal balloon angioplasty is to effectively dilate these proximal vessel segments only, the rationale is based on improving blood flow, oxygenation, and metabolism within the distal arterial territory as well. ${ }^{2,19}$ In instances in which either multiple vessels or a longer portion of the proximal vessel segment are involved, repeated or sequential balloon inflations may be warranted. Additionally, in patients with severe proximal vasospasm, pretreatment with an intraarterial vasodilator may be required to allow navigation of the balloon within the severely stenotic region without obstructing blood flow. Transluminal balloon angioplasty typically has not been used in the distal segments of the cerebral vasculature, primarily because of safety concerns related to the thinner arterial wall and the added technical challenges of navigating more distally in the cerebrovasculature. $6,7,13,25-27,49$

In comparison with the intraarterial injection of pharmacological agents, the limitations of transluminal balloon angioplasty include difficulty with access to distal vasospastic segments and the inability to apply this technique in instances in which a patient has an untreated ruptured aneurysm at or distal to the vasospastic portion of the vessel. ${ }^{60}$ Transluminal balloon angioplasty in patients with unruptured distal aneurysms is regarded as contraindicated because of the potential to induce rupture with augmentation of blood flow to the aneurysm. Potential complications of transluminal balloon angioplasty have been noted in the literature, and include vessel rupture, vessel perforation, thromboembolic events, intracranial hemorrhage, arterial dissection, reperfusion injury, and hemorrhage from unsecured aneurysms. Major complication rates of 4 to $6 \%$ are typically reported. Vessel rupture, virtually a universally fatal event, occurs in approximately $1 \%$ of patients, but was reportedly as high as $7.7 \%$ in one series in which transluminal balloon angioplasty was performed prophylactically within the first 72 hours of an SAH. ${ }^{44}$

The precise mechanism by which transluminal balloon angioplasty results in reversal of cerebral vasospasm remains incompletely understood. Furthermore, the durability of the procedure and the reasons for the low rate of recurrent spasm on the treated segment of the vessel remain to be elucidated. ${ }^{9,37}$ Using the scanning electron microscope, Yamamoto, et al. ${ }^{67}$ examined changes in the three-dimensional structure of connective tissues in vessel walls after balloon angioplasty. The results showed that the normal structure of collagen fibers in the vessel walls was significantly affected by balloon dilation, with stretched and torn fibers observed when $3 \mathrm{~atm}$ of pressure was applied. The endothelium, however, was not found to be damaged. These investigators concluded that balloon dilation caused a mechanical disruption of the proliferating
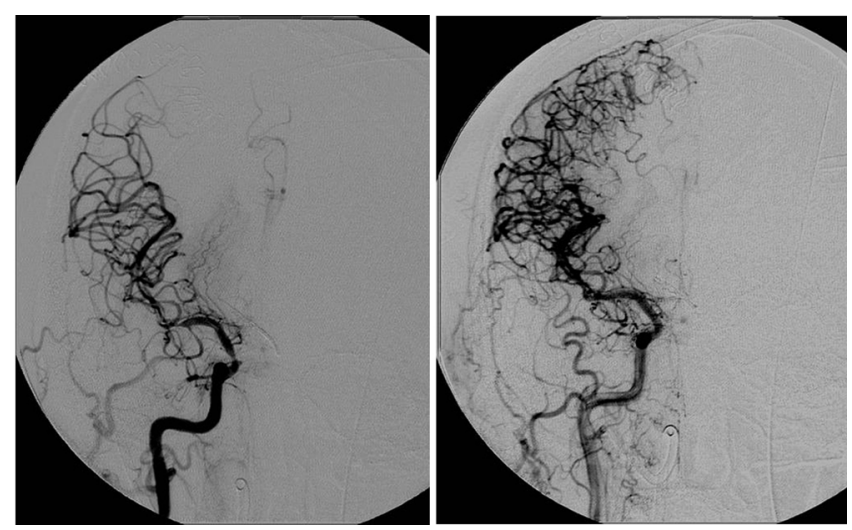

FIG. 1. Left: Pretreatment anteroposterior angiographic view of the right ICA demonstrating moderate to severe stenosis of the supraclinoid segment and the MCA. Right: Postangioplasty anteroposterior angiographic view of the right ICA demonstrating marked improvement in the previously noted vasospasm.

connective tissues in the vasospastic vessel wall, resulting in the prolonged effect of the procedure. In several other human autopsy and animal studies, researchers have demonstrated a similar mechanism to explain the effects of transluminal balloon angioplasty (that is, compression of the connective tissue, which proliferates during cerebral vasospasm; stretching of the internal elastic lamina; and a combination of compression and stretching of the smooth muscle). ${ }^{30,69}$

\section{Intraarterial Papaverine}

In 1992, 8 years after Zubkov first reported his experience with transluminal balloon angioplasty for treatment of cerebral vasospasm, Kaku and colleagues ${ }^{31}$ published an account of their use of intraarterial papaverine injections to treat cerebral vasospasm. Papaverine is an opium alkaloid derived from the opium poppy that causes vasodilation by an incompletely understood mechanism, although it is thought to alter adenosine $3^{\prime}, 5^{\prime}$-cyclic monophosphate levels in smooth-muscle cells. Enthusiasm for papaverine as a vasodilating agent for the treatment of vasospasm flourished in hopes that it could potentially treat previously inaccessible distal vasospastic vessel segments. Many reports detail the clinical results and complications of this technique, although significant criticism of intraarterial papaverine has curbed some of the initial enthusiasm for this therapy. 2,10,12,19,32,40,68

Although papaverine administration clearly results in transient reversal of cerebral hypoperfusion with improvement in blood flow velocities measured using TCD ultrasonography and CBF studies after treatment, ${ }^{15,19,49,64}$ opponents cite the medication's relatively short half-life and short duration of beneficial effects as significant drawbacks. In a prospective study, Vajkoczy, et al. ${ }^{64}$ reported that intraarterial papaverine resulted in only a transient increase in CBF, stating that the beneficial effect of this treatment on cerebral hypoperfusion dissipated within 3 hours after it was administered. In several other studies, investigators have also demonstrated similarly transient benefits. ${ }^{15,43}$ Another concern is the frequent recurrence of vasospasm after intraarterial papaverine administration, 
which often necessitates repeated injections. Repeated intraarterial papaverine injections have been associated with worse clinical outcomes in several reports. $22,54,56$

Elevated ICP following intraarterial papaverine injections has also been a major safety concern. $2,12,28,40,64$ The ICP increases occurred in as many as $42 \%$ of patients in one study and resulted in death in $10 \%$ of the treated patients. Increased ICP after intraarterial papaverine injection was also significantly associated with adverse outcomes. The leading hypothesis posits that papaverine invokes a vast nonselective vasodilatory effect on the cerebrovasculature, resulting in increased $\mathrm{CBF}$ and venous capacitance, perhaps explaining these observed ICP elevations. ${ }^{40}$ In light of these issues, some practitioners discourage its use for treatment of bilateral diffuse vasospasm, and ICP monitoring during administration of intraarterial papaverine has become standard practice. ${ }^{12}$

Intraarterial delivery of papaverine preserved with chlorobutanol has also been associated with marked neurological deterioration and selective gray matter changes on magnetic resonance imaging. ${ }^{61}$ This effect is consistent with a permanent toxic effect to the human brain. It is unclear whether this toxicity is caused by papaverine or chlorobutanol, and some believe it should be reserved for cases in which there are no alternatives. Other less frequent complications that merit brief mention include monocular blindness secondary to crystal emboli formation (papaverine precipitate formation), brainstem dysfunction with respiratory and hemodynamic compromise, seizure, and other transient focal neurological deficits. ${ }^{55}$ At our institution, we no longer use intraarterial papaverine in patients with vasospasm, because of the previously stated concerns.

\section{Other Pharmacological Agents}

The aforementioned limitations of papaverine infusion have led to experimentation with other pharmacological agents. In several studies, investigators have demonstrated that calcium antagonists reduce the proportion of patients with poor outcome and ischemic neurological deficits after aneurysmal SAH. ${ }^{1,5,39,41,42,48,51,52,65}$ Because of these findings, interest in the intraarterial application of these agents has progressed. It is important to note, however, that the intraarterial administration of these pharmacological agents has not been approved by the Food and Drug Administration and that their intraarterial delivery is regarded as an off-label use.

\section{Intraarterial Nicardipine}

Nicardipine, a dihydropyridine calcium channel blocker, conveys a greater selective arterial dilatory effect on vascular smooth muscle than the cardiac muscle. The therapeutic effect is believed to be related to the selective inhibition of transmembrane calcium ion influx into vascular smooth muscle, resulting in a reduction of free calcium ions in these cells and disrupting the actin-myosin interaction essential to muscle contraction ${ }^{47}$ The relative tissue selectivity of nicardipine is also critical in minimizing the cardiac sequelae (including atrioventricular and sinoatrial node conduction suppression and negative inotropic effects) that have been observed in association with other calcium channel blockers (Table 1).
TABLE $1 *$

Relative cardiovascular effect rankings of selected calcium channel blockers $\dagger$

\begin{tabular}{lccc}
\hline \hline \multicolumn{1}{c}{ Agent } & $\begin{array}{c}\text { Negative } \\
\text { Inotropic } \\
\text { Effect }\end{array}$ & $\begin{array}{c}\text { Suppression } \\
\text { Automaticity } \\
\text { (SA node) }\end{array}$ & $\begin{array}{c}\text { Suppression of } \\
\text { Conduction } \\
\text { (AV node) }\end{array}$ \\
\hline nicardipine & 0 & 1 & 0 \\
nifedipine & 1 & 1 & 0 \\
nimodipine & 1 & 1 & 0 \\
verapamil & 4 & 5 & 5 \\
\hline
\end{tabular}

* Compiled from data in Hardman and Limbird (eds), Goodman \& Gilman's The Pharmacological Basis of Therapeutics, ed. 9. New York: McGraw-Hill, 1996.

$\dagger$ Rankings range from no effect (0) to maximal effect (5). Abbreviations: $\mathrm{AV}=$ atrioventricular; $\mathrm{SA}=$ sinoatrial

Much of the research evaluating the efficacy of calcium channel blockers as spasmolytic agents originated from the cardiothoracic surgery literature during the study of coronary artery bypass grafting with arterial conduits. In an in vitro study by $\mathrm{He}$ and Yang, ${ }^{24}$ the spasmolytic effects of nicardipine, nifedipine, verapamil, and diltiazem were studied in the human radial artery. The results show that the dihydropyridines (nifedipine and nicardipine) were better spasmolytic agents than verapamil or diltiazem. Specifically, they were more potent in reversing the existing contraction and in preventing the potassium-induced contraction in the radial artery. Verapamil and diltiazem, however, had no effect on the prevention of contraction in the radial artery. In another study, Radermecker and colleagues ${ }^{57}$ reported outcomes in patients who underwent myocardial revascularization for which the radial artery was used. Hydrostatic dilation of the graft was performed using a diluted solution of papaverine (1\%), and intravenous nicardipine was infused perioperatively. Angiography performed between Days 8 and 10 in the last 20 patients showed a 95\% patency in the radial artery grafts, demonstrating that nicardipine is at least as effective as the diltiazem protocol.

Additional rationales for the use of nicardipine stem from its efficacy in preventing vasospasm by several innovative modes of administration, including intrathecal infusion and subarachnoid implantation. ${ }^{35,63}$ Kasuya and colleagues ${ }^{34-36}$ used nicardipine prolonged-release implants at the time of craniotomy to prevent vasospasm in patients with SAH. Ninety-seven consecutive patients who were treated within 72 hours of their SAH were evaluated. These investigators found that in four $(6 \%)$ of the 69 patients treated with nicardipine prolonged-release implants and in three (11\%) of the 28 patients who were not treated with these implants, delayed ischemic neurological deficits developed. They suggest that the incidence of these deficits may decrease and unfavorable outcomes may improve if nicardipine prolonged-release implants are used in patients with SAH, especially in patients with Fisher Grade 3 SAH.

Although intraarterial nicardipine infusion can be considered a novel concept whose efficacy remains to be proven, Badjatia and colleagues ${ }^{3}$ recently reported their findings over a 12-month span in which they prospectively used intraarterial nicardipine to treat symptomatic vaso- 
spasm in 44 vessels in 18 patients. They reported immediate angiographically confirmed dilation after intraarterial nicardipine infusion in all treated vessels, and no patient sustained cardiovascular changes after the treatment. The ICP was transiently elevated in five patients and persistently elevated in one, but this was not associated with the rate of drug administration. The mean peak systolic velocities measured using TCD ultrasonography were significantly reduced from pretreatment values in all treated vessels for 4 days after infusion, demonstrating a more sustained effect than that shown for papaverine. Further studies are warranted to determine the safety and efficacy of this procedure.

\section{Intraarterial Verapamil}

Intraarterial verapamil, a calcium channel blocker, is currently being investigated at our institution. As of this writing, no literature evaluating the efficacy of this agent had been published. However, the safety of this agent has been studied by Feng and colleagues, ${ }^{18}$ who reported their 2-year experience with intraarterial verapamil as an adjunct therapy to transluminal balloon angioplasty. They retrospectively reviewed 29 patients who received intraarterial verapamil in 34 procedures for vasospasm after aneurysmal SAH in three different settings: 1) before balloon angioplasty, to prevent catheter-induced vasospasm (16 patients); 2) for treatment of mild vasospasm that did not warrant angioplasty (13 patients); and 3) for treatment of moderate to severe vasospasm that could not be safely treated with balloon angioplasty (five patients). The mean dose of verapamil per patient was $3 \mathrm{mg}$ or $44 \pm 5 \mu \mathrm{g} / \mathrm{kg}$. No significant change in heart rate and blood pressure was observed at 10 minutes after administration of the drug. Patients showed no signs of increased ICP based on hemodynamic parameters, neurological examination, or CT scans of the brain. Thus, the investigators concluded that low-dose intraarterial verapamil was safe in these settings. The efficacy of the drug, however, was not assessed because this was not the goal of the study and because the effects of intraarterial verapamil were evaluated angiographically in only 10 of the 18 patients in whom the authors reported data. We are currently studying the efficacy and safety of high-dose intraarterial verapamil at our institution (Fig. 2).

\section{Neurological Outcomes}

Several techniques have been used to quantify the effect of transluminal balloon angioplasty and the intraarterial administration of papaverine on arterial blood flow; these include hemispheric CBF studies (using a ${ }^{133} \mathrm{Xe}$ clearance assay and serial single-photon emission CT scans), blood flow velocities measured using TCD ultrasonography, and angiographic measurements of cerebral artery diameter. Transluminal balloon angioplasty has been shown to improve blood flow velocities on TCD ultrasonography studies obtained postprocedurally in 39 to $100 \%$ of patients in a number of series. ${ }^{16,45,46,49,53} \mathrm{Hoh}$ and Ogilvy ${ }^{28}$ reviewed selected reports in the English language literature and found that $56(69 \%)$ of 81 patients in these studies demonstrated an improvement in blood flow velocities measured using TCD ultrasonography after transluminal balloon angioplasty. In other studies in which ${ }^{133} \mathrm{Xe}$ clear-

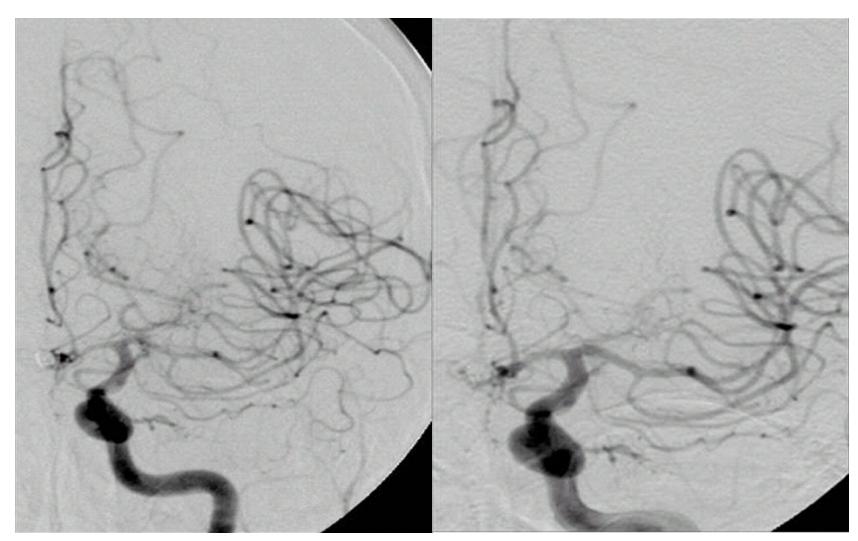

FIG. 2. Left: Pretreatment anteroposterior angiographic view of the left ICA revealing severe spasm of the ACA and MCA caused by SAH. Right: Angiogram of the left ICA obtained after intraarterial administration of $10 \mathrm{mg}$ verapamil over the course of 10 minutes, demonstrating significant improvement in the previously spastic segments.

ance techniques ${ }^{16,19,49}$ and single-photon emission $\mathrm{CT}^{15,21,45}$ were used, improvement in $\mathrm{CBF}$ after transluminal balloon angioplasty was also found, with 58 to $90 \%$ and 60 to $80 \%$ of patients, respectively, demonstrating improvement in CBF on neuroimaging studies obtained with these techniques. Despite the reduced blood flow velocities demonstrated on TCD ultrasonography and the improved CBF demonstrated after transluminal balloon angioplasty and papaverine infusion in many clinical series, the benefit in terms of neurological outcome has been much more

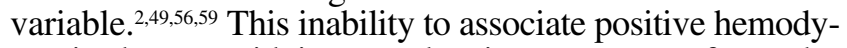
namic changes with improved patient outcomes after endovascular therapy may have many potential explanations.

Because virtually all of the series published so far have been retrospective reviews of the clinical experience with endovascular treatment modalities, they were not designed to evaluate outcomes but rather the efficacy and safety of the procedures. The conclusions garnered may make detecting the beneficial effects of a particular therapy difficult to appreciate because of the study design. One example illustrating this dilemma is evident when one compares patients treated with one of three therapies: transluminal balloon angioplasty only, intraarterial papaverine only, or both therapies. The endovascular neurosurgeon must decide what treatment to use only after the patient has undergone an angiogram and vasospasm is localized and/or characterized. Papaverine traditionally has been used with distal vessel vasospasm and is less commonly used for vasospasm in proximal vessels. Thus, there would always be an intrinsic difference in these two patient groups by virtue of the selection bias inherent in the decision-making process. Furthermore, there is currently a limited understanding of the clinical ramifications of distal compared with proximal vasospasm as it relates to neurological outcome.

Timing of the endovascular intervention relative to the onset of ischemic symptoms may also be a significant factor in evaluating clinical outcomes. The starting point of intervention, be it triple- $\mathrm{H}$ therapy or endovascular intervention, is not well defined in most studies. It remains challenging to assess whether one could correlate better 
outcomes with a particular window of opportunity in which to use transluminal balloon angioplasty. Clearly, the basis for early intervention in patients in whom medical therapy for cerebral vasospasm has failed is to restore perfusion as quickly as possible to an ischemic area distal to the stenotic segment.

In the retrospective series without case controls reported by Rosenwasser, et al., ${ }^{59}$ the window of time during which angioplasty would be most effective in reversing neurological decline and ultimately improving outcome was evaluated. Fifty-one patients underwent endovascular management of ischemia within a 2-hour window, and 33 underwent treatment more than 2 hours after the development of their symptoms. All patients underwent mechanical angioplasty and, if distal vasospasm was present, papaverine was administered. The group that underwent endovascular treatment within the 2-hour window after the development of symptoms demonstrated sustained clinical improvement when compared with the latter group at 6 months $(\mathrm{p}<0.01)$. It is important to note, however, that many other factors, including the cerebrovascular reserves of individual patients and the presence or absence of comorbidities such as cardiovascular disease, may influence the outcome, in conjunction with how quickly endovascular treatment is started.

A worse clinical grade and older age are also negative prognostic factors in patients with SAH. Elderly individuals may suffer less vasospasm but may be more affected by it. We now appreciate that older age is associated with worse recovery after $\mathrm{SAH} .{ }^{8,38}$ Also, the proportion of patients with poor-grade SAH may vary substantially between studies, and this factor may affect outcome. For example, Rosenwasser, et al., ${ }^{59}$ and Bejjani, et al., ${ }^{7}$ reported that 10 and $13 \%$ of their patients, respectively, presented with poor-grade SAH. Their outcomes were much better that those reported by Rabinstein, et al., ${ }^{56}$ who noted that $36 \%$ of the patients in their series presented with poor-grade SAH. This may explain data showing diminished effectiveness of endovascular therapy, as measured by reductions in functional disability, for symptomatic vasospasm as the age of the patient increases.

Last, an emerging concept that needs to be more thoroughly investigated is the stratification of endovascular therapy based on mono- and multiterritorial cerebral vasospasm involvement. Andaluz, et al., ${ }^{2}$ reported on the University of Cincinnati experience and found that this stratification may have implications for neurological outcome, although the authors acknowledged significant differences between these two groups, making the interpretation of these data more difficult. However, several important questions with regard to the distribution of vasospasm and the effect this would have on outcome were nevertheless raised. Perhaps future classifications incorporating the region of vessel involvement (proximal compared with distal) with the distribution of the vasospasm (mono- compared with multiterritorial) would facilitate the development of some sort of treatment algorithm or rationale for these therapies.

\section{Conclusions}

Transluminal balloon angioplasty and the intraarterial infusion of various pharmacological agents provide uni- que opportunities to reverse cerebral vasospasm in patients in whom medical therapy has failed and who would otherwise be without treatment options. Active investigation of the safety and efficacy of several pharmacological agents is ongoing. Developing a sound rationale for the implementation of these techniques in addition to identifying suitable patients to treat will be critical to the clinical results obtained using these measures. Future studies in which the various experiences with each of these treatment modalities are detailed will provide meaningful contributions to our growing body of knowledge on this important topic.

\section{Acknowledgment}

We thank Ms. Jessica Kazmier for her meticulous editorial assistance.

\section{References}

1. Allen GS, Ahn HS, Preziosi TJ, Battye R, Boone SC, Boone $\mathrm{SC}$, et al: Cerebral arterial spasm-a controlled trial of nimodipine in patients with subarachnoid hemorrhage. N Engl J Med 308:619-624, 1983

2. Andaluz N, Tomsick TA, Tew JM Jr, van Loveren HR, Yeh HS, Zuccarello M: Indications for endovascular therapy for refractory vasospasm after aneurysmal subarachnoid hemorrhage: experience at the University of Cincinnati. Surg Neurol 58:131-138, 2002

3. Badjatia N, Topcuoglu MA, Pryor JC, Rabinov JD, Ogilvy CS, Carter BS, et al: Preliminary experience with intra-arterial nicardipine as a treatment for cerebral vasospasm. AJNR Am J Neuroradiol 25:819-826, 2004

4. Baldwin ME, Macdonald RL, Huo D, Novakovic RL, Goldenberg FD, Frank JI, et al: Early vasospasm on admission angiography in patients with aneurysmal subarachnoid hemorrhage is a predictor for in-hospital complications and poor outcome. Stroke 35:2506-2511, 2004

5. Barker FG II, Ogilvy CS: Efficacy of prophylactic nimodipine for delayed ischemic deficit after subarachnoid hemorrhage: a metaanalysis. J Neurosurg 84:405-414, 1996

6. Barnwell SL, Higashida RT, Halbach VV, Dowd CF, Wilson CB, Hieshima GB: Transluminal angioplasty of intracerebral vessels for cerebral arterial spasm: reversal of neurological deficits after delayed treatment. Neurosurgery 25:424-429, 1989

7. Bejjani GK, Bank WO, Olan WJ, Sekhar LN: The efficacy and safety of angioplasty for cerebral vasospasm after subarachnoid hemorrhage. Neurosurgery 42:, 1998

8. Carter BS, Buckley D, Ferraro R, Rordorf G, Ogilvy CS: Factors associated with reintegration to normal living after subarachnoid hemorrhage. Neurosurgery 46:1326-1334, 2000

9. Chan PD, Findlay JM, Vollrath B, Cook DA, Grace M, Chen $\mathrm{MH}$, et al: Pharmacological and morphological effects of in vitro transluminal balloon angioplasty on normal and vasospastic canine basilar arteries. J Neurosurg 83:522-530, 1995

10. Clouston JE, Numaguchi Y, Zoarski GH, Aldrich EF, Simard JM, Zitnay KM: Intraarterial papaverine infusion for cerebral vasospasm after subarachnoid hemorrhage. AJNR Am J Neuroradiol 16:27-38, 1995

11. Coyne TJ, Montanera WJ, Macdonald RL, Wallace MC: Percutaneous transluminal angioplasty for cerebral vasospasm after subarachnoid hemorrhage. Can J Surg 37:391-396, 1994

12. Cross DT III, Moran CJ, Angtuaco EE, Milburn JM, Diringer MN, Dacey RG Jr: Intracranial pressure monitoring during intraarterial papaverine infusion for cerebral vasospasm. AJNR Am J Neuroradiol 19:1319-1323, 1998

13. Dion JE, Duckwiler GR, Viñuela F, Martin N, Bentson J: Preoperative micro-angioplasty of refractory vasospasm secondary 
to subarachnoid hemorrhage. Neuroradiology 32:232-236, 1990

14. Ecker A, Riemenschneider PA: Arteriographic demonstration of spasm of the intracranial arteries, with special reference to saccular arterial aneurysms. J Neurosurg 8:660-667, 1951

15. Elliott JP, Newell DW, Lam DJ, Eskridge JM, Douville CM, Le Roux PD, et al: Comparison of balloon angioplasty and papaverine infusion for the treatment of vasospasm following aneurysmal subarachnoid hemorrhage. J Neurosurg 88: 277-284, 1998

16. Eskridge JM, McAuliffe W, Song JK, Deliganis AV, Newell DW, Lewis DH, et al: Balloon angioplasty for the treatment of vasospasm: results of first 50 cases. Neurosurgery 42: 510-517; discussion 516-517, 1998

17. Eskridge JM, Newell DW, Pendleton GA: Transluminal angioplasty for treatment of vasospasm. Neurosurg Clin N Am 1: 387-399, 1990

18. Feng L, Fitzsimmons BF, Young WL, Berman MF, Lin E, Aagaard BD, et al: Intraarterially administered verapamil as adjunct therapy for cerebral vasospasm: safety and 2-year experience. AJNR Am J Neuroradiol 23:1284-1290, 2002

19. Firlik AD, Kaufmann AM, Jungreis CA, Yonas H: Effect of transluminal angioplasty on cerebral blood flow in the management of symptomatic vasospasm following aneurysmal subarachnoid hemorrhage. J Neurosurg 86:830-839, 1997

20. Fisher CM, Kistler JP, Davis JM: Relation of cerebral vasospasm to subarachnoid hemorrhage visualized by computerized tomographic scanning. Neurosurgery 6:1-9, 1980

21. Fujii Y, Takahashi A, Yoshimoto T: Effect of balloon angioplasty on high grade symptomatic vasospasm after subarachnoid hemorrhage. Neurosurg Rev 18:7-13, 1995

22. Hanel RA, Xavier AR, Mohammad Y, Kirmani JF, Yahia AM, Qureshi AI: Outcome following intracerebral hemorrhage and subarachnoid hemorrhage. Neurol Res 24 Suppl 1: S58-S62, 2002

23. Harrod CG, Bendok BR, Batjer HH: Prediction of cerebral vasospasm in patients presenting with aneurysmal subarachnoid hemorrhage: a review. Neurosurgery 56:633-654, 2005

24. He GW, Yang CQ: Comparative study on calcium channel antagonists in the human radial artery: clinical implications. J Thorac Cardiovasc Surg 119:94-100, 2000

25. Higashida RT, Halbach VV, Cahan LD, Brant-Zawadzki M, Barnwell S, Dowd C, et al: Transluminal angioplasty for treatment of intracranial arterial vasospasm. J Neurosurg 71:648-653, 1989

26. Higashida RT, Halbach VV, Dormandy B, Bell J, BrantZawadzki M, et al: New microballoon device for transluminal angioplasty of intracranial arterial vasospasm. AJNR Am J Neuroradiol 11:233-238, 1990

27. Higashida RT, Halbach VV, Dowd CF, Dormandy B, Bell J, Hieshima GB: Intravascular balloon dilatation therapy for intracranial arterial vasospasm: patient selection, technique, and clinical results. Neurosurg Rev 15:89-95, 1992

28. Hoh BL, Ogilvy CS: Endovascular treatment of cerebral vasospasm: transluminal balloon angioplasty, intra-arterial papaverine, and intra-arterial nicardipine. Neurosurg Clin N Am 16:501-516, 2005

29. Hoh BL, Topcuoglu MA, Singhal AB, Pryor JC, Rabinov JD, Rordorf GA, et al: Effect of clipping, craniotomy, or intravascular coiling on cerebral vasospasm and patient outcome after aneurysmal subarachnoid hemorrhage. Neurosurgery 55: 779-789, 2004

30. Honma Y, Fujiwara T, Irie K, Ohkawa M, Nagao S: Morphological changes in human cerebral arteries after percutaneous transluminal angioplasty for vasospasm caused by subarachnoid hemorrhage. Neurosurgery 36:1073-1081, 1995

31. Kaku Y, Yonekawa Y, Tsukahara T, Kazekawa K: Superselective intra-arterial infusion of papaverine for the treatment of cerebral vasospasm after subarachnoid hemorrhage. J
Neurosurg 77:842-847, 1992

32. Kassell NF, Helm G, Simmons N, Phillips CD, Cail WS: Treatment of cerebral vasospasm with intra-arterial papaverine. J Neurosurg 77:848-852, 1992

33. Kassell NF, Torner JC, Haley EC Jr, Jane JA, Adams HP, Kongable GL: The International Cooperative Study on the Timing of Aneurysm Surgery. Part 1: overall management results. J Neurosurg 73:18-36, 1990

34. Kasuya H, Kawashima A, Sasahara A, Onda H, Hori T: Development of nicardipine prolonged-release implants for preventing vasospasm. Acta Neurochir Suppl 77:217-220, 2001

35. Kasuya H, Onda H, Sasahara A, Takeshita M, Hori T: Application of nicardipine prolonged-release implants: analysis of 97 consecutive patients with acute subarachnoid hemorrhage. Neurosurgery 56:895-902, 2005

36. Kasuya H, Onda H, Takeshita M, Okada Y, Hori T: Efficacy and safety of nicardipine prolonged-release implants for preventing vasospasm in humans. Stroke 33:1011-1015, 2002

37. Kobayashi H, Ide H, Aradachi H, Arai Y, Handa Y, Kubota T: Histological studies of intracranial vessels in primates following transluminal angioplasty for vasospasm. J Neurosurg 78: 481-486, 1993

38. Lanzino G, Kassell NF, Germanson TP, Kongable GL, Truskowski LL, Torner JC, et al: Age and outcome after aneurysmal subarachnoid hemorrhage: why do older patients fare worse? J Neurosurg 85:410-418, 1996

39. Mayberg MR, Batjer HH, Dacey R, Diringer M, Haley EC, Heros RC, et al: Guidelines for the management of aneurysmal subarachnoid hemorrhage. A statement for healthcare professionals from a special writing group of the Stroke Council, American Heart Association. Stroke 25:2315-2328, 1994

40. McAuliffe W, Townsend M, Eskridge JM, Newell DW, Grady MS, Winn HR: Intracranial pressure changes induced during papaverine infusion for treatment of vasospasm. J Neurosurg 83:430-434, 1995

41. Mee E, Dorrance D, Lowe D, Neil-Dwyer G: Controlled study of nimodipine in aneurysm patients treated early after subarachnoid hemorrhage. Neurosurgery 22:484-491, 1988

42. Messeter K, Brandt L, Ljunggren B, Svendgaard NA, Algotsson L, Romner B, et al: Prediction and prevention of delayed ischemic dysfunction after aneurysmal subarachnoid hemorrhage and early operation. Neurosurgery 20:548-553, 1987

43. Milburn JM, Moran CJ, Cross DT III, Diringer MN, Pilgram TK, Dacey RG Jr: Increase in diameters of vasospastic intracranial arteries by intraarterial papaverine administration. $\mathbf{J}$ Neurosurg 88:38-42, 1998

44. Muizelaar JP, Zwienenberg M, Rudisill NA, Hecht ST: The prophylactic use of transluminal balloon angioplasty in patients with Fisher Grade 3 subarachnoid hemorrhage: a pilot study. J Neurosurg 91:51-58, 1999

45. Newell DW, Eskridge J, Mayberg M, Grady MS, Lewis D, Winn HR: Endovascular treatment of intracranial aneurysms and cerebral vasospasm. Clin Neurosurg 39:348-360, 1992

46. Newell DW, Eskridge JM, Mayberg MR, Grady MS, Winn HR: Angioplasty for the treatment of symptomatic vasospasm following subarachnoid hemorrhage. J Neurosurg 71:654-660, 1989

47. Oates JA, Brown NJ: Antihypertensive Agents and the Drug Therapy of Hypertension, in Goodman LS, Hardman JG, Limbird LE, Gilman AG (eds): Goodman \& Gilman's The Pharmacological Basis of Therapeutics. New York, McGrawHill, 2001, pp 871-900

48. Ohman J, Heiskanen O: Effect of nimodipine on the outcome of patients after aneurysmal subarachnoid hemorrhage and surgery. J Neurosurg 69:683-686, 1988

49. Oskouian RJ Jr, Martin NA, Lee JH, Glenn TC, Guthrie D, Gonzalez NR, et al: Multimodal quantitation of the effects of endovascular therapy for vasospasm on cerebral blood flow, transcranial doppler ultrasonographic velocities, and cerebral 
artery diameters. Neurosurgery 51:30-43, 2002

50. Pasqualin A, Vivenza C, Rosta L, Licata C, Cavazzani P, Da Pian R: Cerebral vasospasm after head injury. Neurosurgery 15:855-858, 1984

51. Petruk KC, West M, Mohr G, Weir BK, Benoit BG, Gentili F, et al: Nimodipine treatment in poor-grade aneurysm patients. Results of a multicenter double-blind placebo-controlled trial. J Neurosurg 68:505-517, 1988

52. Philippon J, Grob R, Dagreou F, Guggiari M, Rivierez M, Viars P: Prevention of vasospasm in subarachnoid haemorrhage. A controlled study with nimodipine. Acta Neurochir (Wien) 82: 110-114, 1986

53. Polin RS, Coenen VA, Hansen CA, Shin P, Baskaya MK, Nanda A, et al: Efficacy of transluminal angioplasty for the management of symptomatic cerebral vasospasm following aneurysmal subarachnoid hemorrhage. J Neurosurg 92: 284-290, 2000

54. Qureshi AI, Frankel MR: Recognition and management of subarachnoid hemorrhage. Heart Dis Stroke 3:270-274, 1994

55. Qureshi AI, Sung GY, Razumovsky AY, Lane K, Straw RN, Ulatowski JA: Early identification of patients at risk for symptomatic vasospasm after aneurysmal subarachnoid hemorrhage. Crit Care Med 28:984-990, 2000

56. Rabinstein AA, Friedman JA, Nichols DA, Pichelmann MA, McClelland RL, Manno EM, et al: Predictors of outcome after endovascular treatment of cerebral vasospasm. AJNR Am J Neuroradiol 25:1778-1782, 2004

57. Radermecker MA, Grenade T, Cao-Thian SK, Defraigne JO, Lavigne JP, Van Damme $\mathrm{H}$ et al: Nicardipine protocol for CABG using the radial artery clinical and angiographic data. Acta Chir Belg 101:185-189, 2001

58. Reilly C, Amidei C, Tolentino J, Jahromi BS, Macdonald RL: Clot volume and clearance rate as independent predictors of vasospasm after aneurysmal subarachnoid hemorrhage. J Neurosurg 101:255-261, 2004

59. Rosenwasser RH, Armonda RA, Thomas JE, Benitez RP, Gannon PM, Harrop J: Therapeutic modalities for the management of cerebral vasospasm: timing of endovascular options. Neurosurgery 44:975-980, 1999

60. Schuknecht B: Endovascular treatment of cerebral vasospasm following aneurysmal subarachnoid hemorrhage. Acta Neurochir Suppl 94:47-51, 2005

61. Smith WS, Dowd CF, Johnston SC, Ko NU, DeArmond SJ,
Dillon WP, et al: Neurotoxicity of intra-arterial papaverine preserved with chlorobutanol used for the treatment of cerebral vasospasm after aneurysmal subarachnoid hemorrhage. Stroke 35:2518-2522, 2004

62. Suzuki J, Komatsu S, Sato T, Sakurai Y: Correlation between CT findings and subsequent development of cerebral infarction due to vasospasm in subarachnoid haemorrhage. Acta Neurochir (Wien) 55:63-70, 1980

63. Suzuki M, Doi M, Otawara Y, Ogasawara K, Ogawa A: Intrathecal administration of nicardipine hydrochloride to prevent vasospasm in patients with subarachnoid hemorrhage. Neurosurg Rev 24:180-184, 2001

64. Vajkoczy P, Horn P, Bauhuf C, Munch E, Hubner U, Ing D, et al: Effect of intra-arterial papaverine on regional cerebral blood flow in hemodynamically relevant cerebral vasospasm. Stroke 32:498-505, 2001

65. Vollmer DG, Takayasu M, Dacey RG Jr: An in vitro comparative study of conducting vessels and penetrating arterioles after experimental subarachnoid hemorrhage in the rabbit. J Neurosurg 77:113-119, 1992

66. Weir B, MacDonald L: Cerebral vasospasm. Clin Neurosurg 40:40-55, 1993

67. Yamamoto Y, Smith RR, Bernanke DH: Mechanism of action of balloon angioplasty in cerebral vasospasm. Neurosurgery 30:1-6, 1992

68. Zervas NT, Ogilvy CS: Cerebral vasospasm: current clinical management and results. Clin Neurosurg 45:167-176, 1999

69. Zubkov AY, Lewis AI, Scalzo D, Bernanke DH, Harkey HL: Morphological changes after percutaneous transluminal angioplasty. Surg Neurol 51:399-403, 1999

70. Zubkov YN, Nikiforov BM, Shustin VA: Balloon catheter technique for dilatation of constricted cerebral arteries after aneurysmal SAH. Acta Neurochir (Wien) 70:65-79, 1984

Manuscript received June 19, 2006.

Accepted in final form August 4, 2006.

Address reprint requests to: H. Hunt Batjer, M.D., 676 North St. Clair Street, Suite 2210, Chicago, Illinois 60611. email: hbatjer @nmff.org. 